\title{
The Relationship Between Musical Intelligence And Foreign Language Learning: The Case of Iranian Learners of English
}

\author{
Mohammad Bagher Shabani (Corresponding author) \\ Imam Khomeini International University,Qazvin-Iran \\ E-mail: m.b.shabani@ikiu.ac.ir \\ Mahvash Torkeh \\ Imam Khomeini International University,Qazvin-Iran \\ E-mail: mahvashtorkaman@yahoo.com
}

Received: 05-12-2013

doi:10.7575/aiac.ijalel.v.3n.3p.26
Accepted: 07-01-2014

Published: 01-05-2014

URL: http://dx.doi.org/10.7575/aiac.ijalel.v.3n.3p.26

\begin{abstract}
This study examined the relationship between musical intelligence and foreign language learning. First, it will focus on the relationship between music and language and potential advantages of inclusion of music in teaching and learning a foreign language. Second, it will present the result of the study of Persian learners of English by the age of 15 to 18 . The result of study suggests that musical intelligence significantly correlates with learning foreign language and it may facilitate learning of foreign languages.
\end{abstract}

Keywords: music, language, musical intelligence, foreign language learning.

\section{Introduction}

Music is an indispensable part of human beings' life and culture. It is one of the oldest and most basic socio-cognitive domains of the human being. Music serves various purposes in our life. It provides enjoyment, pleasure, motivation, relaxation, and a tool for learning. It enhances the functioning of the immune system. The tempo and genre of musical selection affects heart rate, blood pressure, respiration, and body temperature. It develops memory through melody and beat, and through its connection to the emotions. Finally, music can improve coordination and the ability to listen and respond (Sakamoto, 2000).

Learning a foreign language is a hard task. Many factors intervene to reach an optimal result of learning a foreign language in a non-bilingual environment. One of the main barriers to learn a foreign language is the lack of sufficient target language auditory input which is mainly limited to the classroom and the teacher. Language learning depends on the nature of interaction that can share features such as simplified vocabulary, change in voice, formulaic expressions, and the frequency of repetition, and modification of international patterns. Rhythm and melody of speech have a great impact on communication and they can help language learning (Zybert\&Stepien, 2009).

There are common features in music and language. For example, many different styles of music have a series of strict rules which in a way resemble grammar, or each culture has its own specific style of music and a particular way of perceiving it. Music, like language, has rhythm; stress, pitch, and distinct elements of little intrinsic meaning which are combined to make structures with a great difference meaning. Both of them convey meaning, feeling, and emotion (Lerdahl\&Jackendofe, 1983).

Patel (2008) states that Broca's area is not only responsible for the syntax function of language but it is also, involved in processing of musical syntax. Cognitively, the neuro- function of music is processed in the right hemisphere. Zatorre and Samson(1991) found that patients with right hemisphere trauma are most likely to have musical perception skills and that aphasic patient with left hemisphere damage often have intact musical competence. Schellenberg (2007) points out neural activities associated with listening to music, work deeper in the auditory cortex influencing the frontal, temporal, parietal and subcortical areas which are related to attention. Arnold (1999) points out that "we learn better that which attracts our attention, and emotion automatically makes us pay attention" (p.260).He further maintains that this is what music does in a language learning process.

The role of music in learning can be specified in terms of enhancement of social harmony and motivation in working in group. Utility of learning and teaching social harmony is necessary in classroom. Children often sing together and realize the feeling of togetherness. Music in the class is applied to calm the mind, to relax muscles and enables learners to be free from pressure and stress (Mashayekh\&Hashemi, 2011). Music is purposely used to teach language and culture. Using music in the classroom can create a soothing atmosphere for learners and helps them not to feel threatened. It also can strengthen the relationship between teacher and students. Sleve and Miyake (2006) claim that learning a new language can benefit from structural and motivational properties of music in songs because these musical activities can develop auditory perception and metacognitive knowledge and aid phonological memory. They 
continue that music and songs can increase sensibility, aid memory, improve concentration, and help develop reading and writing abilities. Jolly (1975) states that the use of songs in lessons can improve four skills of language: listening, speaking, reading and writing. Songs activate both parts of the brain. The pronunciation of words, understanding, rhythm and musical execution correspond to the left hemisphere, whereas, melodic expression, emotions, and tone correspond to the right hemisphere. Kraus and Chandrasekaran (2010) state that musical training develops auditory skills as well as verbal memory. Listening to songs and singing them improve listening skills in a foreign language that is one of the essential skills for language learning. Ehri (2001) believes that if a person is not able to distinguish between the phonemes and intonation which differentiate the target language from the mother tongue, it will be impossible to learn the target language so children with poor phonemic awareness in L1 will show lower levels of progress with respect to the learning of foreign languages. Singing songs is an activity that combines linguistic and musical information throughout the corpus callosum, connect both hemispheres, which fortify the conveyance of messages. Several studies (Milovanov\&Gustafasson, 2004; Salcedo, 2002; Goldsmith, 210) have shown that singing songs can develop pronunciation, grammar, and vocabulary of language.

Gardner (1993) defines Musical Intelligence as greater sensitivity to sounds, rhythms, tones, and music. In fact, it is the ability to perceive and appreciate rhythm, pitch and melody, elements which are crucial in the language learning process. Churchy (1967) states that melodies in teacher talk cause pauses that can provide opportunity for learners to process the input. He further maintains that rhythm can slow the speech production and melody can guide the speaker's pitch variation. Musical intelligence requires interaction within the musical realm. It is the earliest of the intelligences to appear in human being even children as young as two month old can sing and match rhythmic structures (Hallam, 2010). Musical intelligence is closely linked to other intelligences. Gardner (1983) believes that "if we can explain music, we may find the key for all human thought" (p.123). Musical intelligence and skills of music are connected to other cognitive skills, such as linguistic skills, social skills, and the ability to express oneself (Schellenberg, 2005).

Claerr and Gargan(as cited in Salcedo, 1984) state that incorporation of musical methodology into teaching foreign language instructions can be effective. "With some imaginations songs can be used to teach all aspects of foreign languages" (p.31). Suggestopedia was introduced in 1978 by GeorgiLozanov. This method uses classical music to relax the students. Lozanov believed that the relaxation techniques help learners to acquire language structures and vocabulary subconsciously. Suggestopedia can help learners use both the left and the right hemispheres of the brain and provide relaxing conditions that can enhance mental activity and concentration.

According to Krashen (1981), one of the primary principles for language acquisition is that students must have a low level of anxiety in order for the input to be acquired naturally. He believes that Lozarnov's method is a subconscious acquisition that is the result of providing comprehensible input and reducing anxiety in learning situation.

Several studies (Mashayekh\&Hashemi, 2011; Sleve \& Miyake,2006; Milovanov\&Gustafasson,2004; Fonseca-Mora \&Toscano-Fuentes \&Wermke, 2011; ) have indicated that learners with musical aptitude perform better in many fields such as general intelligence, verbal memory, literacy, visual perception and spatial skills. Also, they have shown that there is strong positive correlation between musical intelligence and foreign language proficiency.

The purpose of the present paper is to indicate the relation between musical intelligence as an effective teaching tool in foreign language learning.

\section{Literature of review}

In MI (Multiple Intelligences), Gardner propose eight distinct areas of intelligence, including: verbal-linguistic, visualspatial, mathematical-logical, body-kinesthetic, musical-rhythmic, interpersonal, intrapersonal, and naturalistic (Gardner, 1993). He argues that the linguistic and musical intelligences are separate but they work together which can result in strong and effective cooperation.

Krashen (2009) proposes "input hypothesis". According to this hypothesis, unfamiliar and unknown materials are acquired when they are comprehensible. Meaning that is conveyed through music and song is comprehensible for the learner. He further mentions that learning vocabulary through music and song is a kind of incidental learning and is effective way of acquiring vocabulary of foreign language. Research is done by Medona (1993) seems to indicate that music has strong effect on second language vocabulary acquisition.

John Carroll (1993) divided cognitive abilities into: 1) fluid intelligence, 2) crystallized intelligence, 3) general memory and learning, 4) broad visual perception, 5) broad retrieval ability, 6) broad auditory perception, 7) broad cognitive speediness, and 8) processing speed. He replaced the broad auditory perception as the musical intelligence which can be divided into: 1) Discriminate tones on pitch, intensity, duration, and rhythmic dimensions; 2) Judgments of complex relations among tonal patterns; 3) Discriminate and judge tonal patterns in musicality with respect to melodic, harmonic, and expressive aspects (Carroll, pp.393). Research carried by Hue, \& Ackermann, \& Martin, \&Erb, \& Winkler, and Reiterer (2012) demonstrated that phonetic coding ability can predict L2 pronunciation aptitude in advanced learners. They argue that cognitive factors such as: phonetic coding ability (PCA), music aptitude, empathy, and openness to experience are correlated.

There are several justifications to hypothesize that instruction in music can have effects on acquiring reading skills. First, music and written text both include formal written symbol which are organized from left to right which can be decoded to particular sound and practice in reading music note may encourage the reading of linguistic symbol in a comfortable and convenient way (Zimmermann, 2006). Second, singing of song may be a means to develop good dictation which can result into learning sight vocabulary from written song lyrics (Butzlaff, 2000). A number of studies 
have found that children who participate in music instruction have high ability in reading comprehension than children who do not participate in music instruction. Anvari, Trainor, Woodside, and Levy (2001) examined the relationship among phonological awareness, music perception skills, and early reading skills in a population of 1004 and 5 year-old children. Music skills were found to correlate significantly with both phonological awareness and reading development. Their finding indicated that music perception can stimulate auditory mechanisms related to reading that only partially overlap with phonological awareness. Piro and Oritz (2009) have reported positive association between music and education and increased abilities in non-musical (e.g. linguistic) domains in children. Their result showed that the music-learning group had significantly better vocabulary and verbal sequencing score than the none-musical learning control group. Then their finding provided evidence to support that by improving these sub skills of reading by instruction in music, the learning skills will be improved.

Another way that music instruction may affect on reading ability is through enhancing verbal memory that has an important role in understanding reading printed words. Verbal memory helps children to store materials in their memory as they are being read. Psychological research carried out by Chen and Cheung (1998) indicated that learners who participated in music instruction could enhance their brain's ability to remember words. They concluded that students with music training could remember $17 \%$ more verbal information than those without music.

Writing and reading are closely related. By improving vocabulary and reading skill, writing can be improved. Research carried out by Register (2011) indicated that instruction in music can enhance the ability to learn prewriting and print concept in children aged 4-5 years.

According to Hugo and Horn (2013), music instruction can be applied to improve and develop learners' listening abilities. Listening skill is a prerequisite for the development of other language skills particularly for the development of learners' abilities. The knowledge gained from their research, indicated that learners who involved in music instruction significantly improved their listening skills in English as second language (ESL). They further maintain that songs can help to make learners aware of fast, slow and medium tempo of spoken English and the learners are enabled to learn new words and idiomatic expression from the songs.

Scientific research supports the role of music instruction in developing phonemic awareness, verbal memory, vocabulary, and developing language skills. The present study is an attempt to investigate the relationship between musical intelligence and foreign language learning among Iranian learners.

\section{Statement of the Research Problem}

Technology progress and the importance of English as an international language are key determinants for new developments for English language teaching in Iran. Learning English as a foreign language is demanding task for the majority of Iranian learners and sometimes, is boring and tedious to them which require motivation and interest. The element of music should be incorporated in Iranian English language teaching instructions in order to enable them to concentrate their inner status, stimulate creative process, and also to develop attractive classroom atmosphere. For enhancing learning a foreign language, creating low anxiety and stress levels is necessary condition which can be satisfied by inserting musical instructions.

Less attention is paid to the importance of incorporating music in Iranian EFL educational system. Moreover, research on the relationship between musical intelligence and foreign language learning is very limited in Iran. The present study is an attempt to fill this gap partially.

\section{Research Question}

In order to get the good result, the present paper is an attempt to find answer to the following question:

1- Is there any significant relationship between Iranian EFL learners' musical intelligence and their English language proficiency test?

\subsection{Research Hypothesis}

In order to cope with the answer of the preceding question, the following hypothesis was proposed:

There is not any significant relationship between Iranian EFL learners' musical intelligence and their English language proficiency test.

\section{The aim of the study}

The major aim of the research is to verify the claim that musical intelligence correlates with success in foreign language learning and that musical training fosters foreign language learning.

\section{Method}

\subsection{Participants}

The participants were 140 Persian native speakers (100 females, 40 males) ages 15 to 18 . They were students in Kish Mehr institution at intermediate level of English language proficiency.

\subsection{Instruments}

To conduct the present study, two instruments were employed: English language proficiency test and a musical intelligence questionnaire (Howard Gardner multiple intelligence questionnaires) 
The language proficiency test was employed to determine the participants' level of English language proficiency as well as their vocabulary and grammar knowledge. It was a three-part, 50-item multiple-choice test containing 30 grammar items, 10 vocabulary items, and reading passages followed by 10 comprehension questions.

The Gardner's musical intelligence test was used to assess the participant's musical intelligence. It was designed to measure some of the important abilities involved in musical intelligence. The questionnaire is reliable and standard one. The translated version of this test prepared and used in order to avoid any misunderstanding.

\subsection{Procedures}

Initially, a multiple-choice 50-item language proficiency test was administered on 140 participants. Then the Gardner's musical intelligence questionnaire, which consisted of 10 items, was administered. To avoid any misunderstanding, it was translated from English language to Persian.

\section{Results}

\subsection{Investigation of the research question}

The research question attempted to find the relationship between musical intelligence and foreign language proficiency. To this end, a Pearson correlation was used. Table 1 summarizes the descriptive statistics and test results for the musical intelligence scores as well as the proficiency test scores of the participants. As Table 1 shows, the correlation coefficient index (0.82) is statistically significant and there is a strong trend towards a positive relationship.

The results of the tests together with appropriate discussions are presented below: the following table presents both Pearson correlations $(\mathrm{r}=0.82)$ and Spearman correlation $(\mathrm{r}=0.82)$, the number of cases $(\mathrm{N}=140)$, and the significance level $(\mathrm{p}<0.005)$.

Table1.Correlation of musical intelligence and proficiency level

\begin{tabular}{|c|c|c|c|}
\hline & & proficiency test & $\begin{array}{c}\text { musical } \\
\text { intelligence test }\end{array}$ \\
\hline \multirow[t]{3}{*}{ proficiency test } & Pearson Correlation & 1 & $.829^{* *}$ \\
\hline & Sig. (2-tailed) & & .000 \\
\hline & $\mathrm{N}$ & 140 & 140 \\
\hline \multirow[t]{3}{*}{ musical intelligence test } & Pearson Correlation & $.829^{* *}$ & 1 \\
\hline & Sig. (2-tailed) & .000 & \\
\hline & $\mathrm{N}$ & 140 & 140 \\
\hline
\end{tabular}

Standardized values, used for establishing the degree of correlation:

$\mathrm{r}<0.2$ : no correlation; $\mathrm{r}=0.2-0.4$ : weak correlation; $\mathrm{r}=0.4-0.7$ : moderate correlation; $\mathrm{r}=0.7-0.9$ : strong correlation; $r>0.9$ : very strong correlation.

Since the probability value (p) is below 0.05 , it demonstrates a statistically significant correlation between musical intelligence and learning foreign language. A correlation of 0.8 indicates a strong correlation. The coefficient of determination of these variables is 0.67 . (0.82.0.82). that means, in this calculation, musical intelligence shares 67 percent of the variance with proficiency test.

In figure 1, the scatter plot clearly illustrates that the relationship between musical intelligence and proficiency test is positive. The direction of the line is from left to right and it also has upward trends. The distribution of scores on the scatter plot and relationship between two variables is roughly linear.

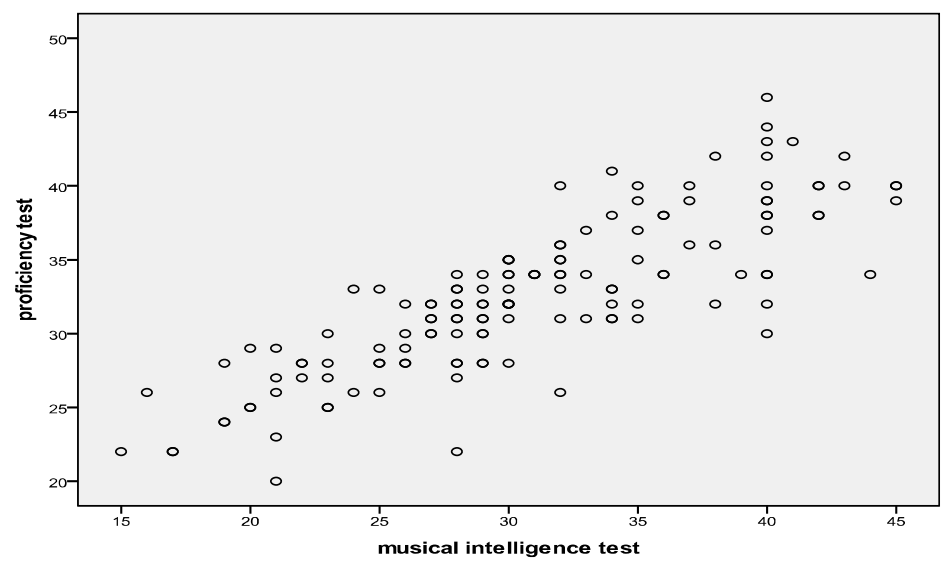

Figure 1. Relationship between musical intelligence and proficiency test. 
Briefly, the statistical results illustrates that there is positive strong correlation between musical intelligence and language proficiency. In other words, high level of musical intelligence correlates with high level of language proficiency.

\subsection{Discussion}

The present study aims at determining whether musical intelligence could be a crucial factor in foreign language proficiency, and at discussing the relationship between music and language in general. To this end, the facilitating role of musical intelligence on foreign language proficiency was observed in adult participants without any learning disabilities.

It is not possible to identify precisely which brain areas are associated with language or music function. Several neuropsychological studies have indicated that music and language are independent cognitive function and it has been suggested that speech sound and musical sounds are encoded independently in the auditory cortex (Alho, Alku, Kujala, Ilvonen\&Tervaniem, 2001). However, the result of study carried out by Maess, Koelsch, Gunter, and Friederici (2001) indicated that there is overlap between music and foreign language learning. Anvari and etal (2002) found out that music perception appears to tap auditory mechanisms related to reading that only partially overlap with those related to phonological awareness. Zybert and Stepien (2009) found that musical intelligence can affect the quality of phonetic performance of EFL students and they claimed that musical intelligence is predictive of success in developing pronunciation accuracy in the target language. A research carried out by Register (2001) indicated that music instruction has significant role in developing prereading and writing. Butzlaff (2002) found a strong reliable association between music instruction and scores test of reading comprehension. Brady (1991) found that music instruction can enable learners to improve their reading skills by improving their verbal memory. This research does suggest that there is strong positive relationship between musical intelligence and foreign language learning. However, a more precise determination of this relationship remains an important question for future research.

\section{Conclusion}

The purpose of the present study was to investigate if music has a positive relationship with learning a foreign language. Although everyone is capable of learning a foreign language to some degree of competence, some learners are better equipped than others. People with high levels of musical intelligence are those who have a high level of sensitivity to sounds or phonology which is a crucial element in learning a foreign language. In general, it can be claimed that inclusion of music program in the learning of foreign language classroom can have benefits such as providing smoothing condition, stimulating creative process, increasing students' motivation for learning, activating linguistic information stored in the memory, helping students to concentrate and connect with their inner self, and improving writing, reading, listening, and speaking skills in language learning process. Specifically, several studies have shown that students with higher levels of musical intelligence perform better in many fields such as verbal memory, vocabulary, and phonemic awareness than other learners with lower levels of musical intelligence.

In order to reach a better understanding of the relation between musical intelligence and language learning process, other factors related to language learning such as sex, age, mother tongue, and so on need to be considered. Inclusion of the result of this study in teaching foreign language can provide teachers with appropriate pedagogical and useful guidelines.

Overall, the study presented in this paper seems to provide considerable evidence to support the assumption that musical intelligence is a determinant and predictor of success in foreign language learning.

In conclusion, it has to be emphasized that musical intelligence and musical training should be regarded as an important factor in the language teaching. Undoubtedly, the question of the influence of musical intelligence on foreign language learning and of the relation between musical and language learning aptitude leaves much room for further research.

\section{References}

Abbott, M. (2002). Using Music to Promote L2 Learning among Adult Learners. TESOL journal, 26(4), 10-17.

Arnold, J. (1999). Affect in Language Learning. UK: Cambridge University Press.

Anvari, S. H., Trainor, L., Woodside, J., \& Levy, B. A. (2002). Relations among Musical Skills, Phonological Processing, and early reading ability in preschool children. Journal of Experimental Child psychology, 83(2), 111-130.

Blickenstaff, C. (2011). Musical talents and foreign language learning ability. Journal of Modern Language, 47(8), 359363.

Brady, S. (1991). The Role of Working Memory in Reading Disability. Published online. Retrieved 30 November 2013 from: www.haskins.yale.edu/sr/SR105-pdf.

Butzlaff, R. (2000). Can music be used to teach reading? Journal of Aesthetic Education, 34(3), 167-178.

Carroll, J. (1993). Human cognitive abilities: A survey of factor-analytic studies. UK: Cambridge University Press.

Chen, A.S., Ho, Y., \& Cheung, M. (1998). Music training improves verbal memory. Journal of Nature, 396(12), 128.

Churchy, F. (1967). Contemporary approach in music education. Journal of Education/Revuedes Sciences, 12(1), 4549. 
Ehri, L. (2001). Phonemic awareness instruction helps children learn to read: Evidence from the national reading panel's meta-analysis. Reading Research Quarterly, 36(3), 250-287.

Fonseca-Mora, M.C., Toscano-Fuentes, C., \& Wermke, K. (2011). The Relationship between language aptitude and musical intelligence. Anglistik international journal of English studies, 22(1), 101-118.

Gardner, H. (1993). Frames of Mind: The theory of Multiple Intelligences. New York: Basic Books Publisher.

Gilleece, L. (2006). An Empirical Investigation of the association between musical aptitude and foreign language aptitude. Published online 30 September 2006.

Goldsmith, B. (2010). Music can boots language skills, improve learning. Published online 21 Jul 2010.

Goodman, K. (2011). Music Therapy Education and Training. USA: Charler Thomas Publisher.

Hallam, S. (2012). The power of music: its impact on the intellectual, social and personal. Published online 21 August 2012.

Hu, X., Ackermann, H., Matrin, J., Erb, M., Winker, S., \& Reitere, S. (2012). Language aptitude for pronunciation in advanced second language (L2) learners: Behavioral Predictors and Neural Substrates. Journal of Brain and Language. Retrieved April, 2013 from www.elsevier.com/locate/b\&l

Hugo, A. \& Horn, C. (2013). Using music activities to enhance the listening skills and language skills of graded 1, English first additional language learners. Journal of Language Learning, 29(1), 63-74.

International Test Commission Publications. (2008). Multiple intelligence quiz. Retrieved from http://www.collegesuccess1.com/instructor/manual4thEd/musicalintelligencequiz.

Jolly, Y. (1975). The use of songs in teaching foreign language. Journal of Modern Language, 59(1), 11-14.

Jaramilo, M., Ilvonen. T., KUjala. T., Alku, P., Tervaniemi, M.,\& Alho, K. ( 2001). Are different kinds of acoustic features processed differently for speech and non-speech sounds? Journal of Cognitive Brain Research, 12(3), 459-466.

Kivy, p. (2007). Music, Language, And Cognition. New York: Oxford University Press.

Krashen, S. (2009). Principles and Practice in Second Language Acquisition. USA: Southern California University Press.

Krashen, S. (1981). Second Language Acquisition and Second Language Learning. California: Pergamon Press.

Kraus, N., \& Chandrasekaran, B. (2010). Music training for the development of auditory skill. Journal of Science and Society, 11(8), 99-605.

Lerdahl, F., \& Jackendoff, R. (1983). A Generative Theory of Tonal Music. Cambridge: MLT Press.

Maess, B., Koelsch, S., Gunter, T.C., \& Friederici, A.D. (2001). Musical syntax is processed in Broca's area: an MEG study. Nature Publishing Group. Retrieved 10 November 2013 from http://neurosci.nature.com.

Mashayekh, M., \& Hashemi, M. (2011). The impact of music on language learners' performance. Journal of social and behavioral science, 30(3), 717-718.

Medonna, S. (1993). The effect of music on second language vocabulary acquisition. National Network for Early Language Learning, 6(3), 1-8.

Milovanov, R. (2009). The Connectivity of Musical Aptitude and Foreign Language Learning Skills: Neural and Behavioral Evidence. Finland: Turku University Press.

Milovanov, R., Tervaniemi, M., \& Gustafsson, M (2004). The impact of musical aptitude in foreign language acquisition. Published online 13 August 2004.

Morgan-Carter, C. (2001). The relation between Musical Ear and L2 Acquisition. Vancouver: University of British Columbia.

Munger, D. (2008). Does music help us learn language? Published online 19 June 2008.

Patel, A. (2008). Music, Language, And the Brain. New York: Oxford Press.

Peynircioglu, Z., Durgunoglu, A., \& Oney-Kusefoglu, B. (2002). Phonological awareness and musical aptitude. Journal of Research in reading, 25(1), 68-80.

Piro, J., \& Ortiz, C. (2009). Music education can help children improve reading skills. Journal of Psychology of Music, 37(3), 325-347.

Quinlan, M. (2013). Transparent Language. Retrieved 11 November 2013 from http://www.Transparent.com/learnenglish/proficiency-test.html.

Raffman, D. (1993). Language, Music, And Mind. London: MIT Press.

Register, D. (2001). The effect of an early intervention music curriculum on pre-reading/ writing. Journal of Music Therapy, 38(3), 239-248.

Sakamoto, H. (2002). Psycho-circulatory responses caused by listening to music, and exposure to fluctuation noise or steady noise. Journal of Sound and Vibration, 250(1), 23-29. 
Salcedo, C. (2002). The effect of songs in the foreign language classroom on text recall and involuntary mental rehearsal. Published doctoral dissertation, University of Louisiana.

Schellenberg, E.G. (2005). Music and cognitive ability. Journal of Psychological Science, 14(6), 317-320.

Sleve, R,. \& Miyake, A. (2006). Individual differences in second language proficiency. Journal of psychological science, 17(8), 675-681.

Snow, C.E., Burns, M.S., \& Griffin, P. (1998). Preventing Reading Difficulties in Young Children. Washington DC: National Academy Press.

Spiro, J. (2003). Music and the brain. Journal of Nature Neuroscience, 6(7), 661-670.

Zatorre, R.J., \& Samson, S. (1991). Role of the right temporal neocortex in retention of pitch in auditory short-term memory. Journal of Brain. Retrieved 12 September 2013 from: http://www.ncbi.hlm.nih.gov/pubmed/17825523.

Zimmermann, L. (2006). A Descriptive Study of the Relationship Between Language Reading Proficiency and the Age At Which Music Lesson Are Begun. Published MA dissertation, University of Silver Lake.

Zybert, J. \& Stepien, S. (2009). Musical intelligence and foreign language learning. Journal of Research in Language, 7(4), 99-111. 